\title{
THE PREVALENCE OF CORONARY HEART DISEASE, STROKE AND SELECTED CO-MORBIDITIES IN PATIENTS WITH NEWLY DIAGNOSED TYPE 2 DIABETES POPULATION $\div$ BASED ON COHORT STUDY OF OUTPATIENTS
}

\author{
Bukova L. ${ }^{1}$, Galajda P. ${ }^{2}$, Mokan M. ${ }^{2}$ \\ ${ }^{1}$ Clinic of Internal Medicine, Faculty Hospital F.D.Roosevelt in Banska Bystrica, Outpatient Department for \\ Diabetes \\ ${ }^{2}$ Clinic of Internal Medicine I, Jessenius Faculty of Medicine, Comenius University and University Hospital in \\ Martin, Slovakia
}

\begin{abstract}
The prospective study analyses prevalence of coronary heart disease, stroke, elevated serum levels of ALT and GGT and prevalence of cancer diseases in patients with newly diagnosed type 2 diabetes mellitus, and usage of this epidemiological data in everyday clinical practice. Outpatients with newly diagnosed type 2 diabetes mellitus were monitoring during the period of August 2007 - August 2011. The patients with previously treated type 2 diabetes mellitus were eliminated from the monitoring. The population consists of 117 males and 83 females aged 30 to 92 years sent by GPs and various specialists.

The relatively low prevalence of known coronary artery disease was recorded in men (34\%) and in women (19\%). Prevalence of stroke history was confirmed in $12 \%$ of men and $7 \%$ of women. The elevated serum ALT levels $>0.55$ $\mu \mathrm{kat} / \mathrm{l}$ was recorded in $45 \%$ of men and $45 \%$ of women and elevated serum GGT levels $>0.45 \mu \mathrm{kat} / \mathrm{l}$ was recorded in $81 \%$ of men and $68 \%$ of women. Prevalence of cancer diseases was recorded $5 \%$ in women and $5.26 \%$ of men. In the studied group of patients there was recorded the occurrence of colon cancer in men over 64 years old and the occurrence of breast cancer, endometrial cancer and colon cancer in women over 62 years old.
\end{abstract}

Key words: prevalence, newly diagnosed type 2 diabetes mellitus, stroke, coronary heart disease, cancer, steatosis

\section{INTRODUCTION}

Cardiovascular (CV) disease remains a leading cause of death in developed countries and excess mortality from cancer. High mortality from cardiovascular disease is related to the increasing prevalence of the metabolic syndrome and type 2 diabetes mellitus. Coronary heart disease occurs in patients with type 2 diabetes early and is more difficult than in non diabetics (1). Screening for macrovascular complications at time of diagnosis of type 2 diabetes would be useful in determing individual treatment target values. Strict glycemic control may not be as beneficial in patients with macrovascular complications. ACCORD (Action to Control Cardiovascular Risk in Diabetes) and ADVANCE (Action in Diabetes and Vascular Disease: Preterax and Diamicron Modified Release Controlled Evaluation) studies tried to measure the impact of strict glycemic control of cardiovascular risk. The conclusion of both studies was, that intensive treatment type 2 diabetes in the person from 3.5 to 5 years did not show any reduction of cardiovascular events $(2,3,4)$.

Patients with pre-existing CV disease or multiple CV risk factor are not eligible for intensive treatment to achieve HBAlc target values to the normal non-diabetic ranges. As the problem can be hypoglycemia leading to cardiac contractility disturbances and to cardiovascular events and stroke. We have long known that intensive glycemic control can reduce the incidence of microvascular complications. Study ADVANCE have confirmed the reduction of microalbuminuria and nephropathy (2). It is advisable to evaluate screening methods for detecting latent cardiovascular disease.

Address for correspondence:

Linda Bukova MD, Clinic of Internal Medicine, Faculty Hospital F.D.Roosvelt in Banska Bystrica, Outpatient Department of Diabetes

phone: +421908532428; e-mail: linda.bukova@inmail.sk 
According to the Demographic Research Centre the life expectancy of the Slovak women in 2008 was 78 years and of the Slovak men was 70.4 years. For comparison, the life expectancy in 2008 of the German women was 84 years and of the French women was 83 years. The life expectancy in 2008 of the German men was 76.5 years and of French men was 75.9 years (5). This difference is probably related to the standard of living between countries, which includes better quality and variety of food in countries with higher life expectancy. Table No.1 shows the mortality rates per 100000 people for coronary heart disease (CHD) in the countries of the European Union (EU) in 2010 (6). According to the Eurostat data published in 2012 standardised death due to coronary heart disease in Slovakia was 263 per 100000 population (i.e. the second highest in the EU countries). We need to take into account a routine presentation of selected cardiovascular disease as a cause of death which is a frequently encountered loading situation in practice and may significantly affect the statistical results. In this time in the Slovak Republic is created a National Register of patients with type 2 diabetes which could specify the data of coronary heart disease mortality in patients with type 2 diabetes. This Register could compare the mortality in diabetic and non - diabetic subjects. The data form Register could facilitate international comparisons.

Table 1. Standardised death due to CHD in EU per 100000 population in 2010 (6)

\begin{tabular}{|l|l|l|l|l|c|l|l|l|l|l|l|}
\hline Romania & 187 & Poland & 90,6 & Ireland & 91.2 & Denmark & & Sweden & 79.6 & Spain & 43.8 \\
\hline Bulgaria & 114 & Czech & 161 & Estonia & 199 & Cyprus & 64 & Malta & 106 & Portugal & 40.8 \\
\hline Hungary & 215 & Austria & 96 & UK & 77.3 & Belgium & & Finland & 120.7 & & \\
\hline Slovakia & 263 & Lithuania & 313 & Greece & 62.1 & Italy & 54.6 & France & 30 & & \\
\hline Slovenia & 63.6 & Germany & 80.9 & Netherlands & 40.6 & Luxemburg & 45.2 & Latvia & 248 & & \\
\hline
\end{tabular}

Non-alcoholic fatty liver disease (NAFLD) is now recognized as the most common cause of liver disease and accidental elevation mainly alanine-aminotransferase (ALT) and glutamyl transferase (GGT). The prevalence of NAFLD in different countries related to the prevalence of the metabolic syndrome. Insulin resistance is an independent predictive factor for steatosis and also a predictive factor for the transition to NASH (nonalcoholic steatohepatitis) and hepatic fibrosis, respectively. Currently steatofibrosis is one of the causes of liver transplantation. The actual prevalence of NAFLD in other countries is unknown. In the US, NAFLD is estimated to affect from $20 \%$ to $30 \%$ of the general population. Prevalence of NASH ranges from 3.5 to $5 \%$ (7). The boundary between steatosis and steatohepatitis is histological (8). It is estimated, that in $12-40 \%$ of NASH patients develop early fibrosis. Advanced hepatic fibrosis is found in $5-10 \%$ of patients and about half of them will result in cirrhosis. Over a 10 year period hepatocellular carcinoma occurs in $7 \%$ of them (7) Overall it is estimated that in about $15-30 \%$ of NASH may occur cirrhosis over a 10 year period (9).

Metabolic syndrome and type 2 diabetes are associated with an increased incidence of cancer: breast, colorectal, hepatocellular, pancreas, endometrial and bladder (10). Some studies bring correlation between type 2 diabetes and lymphoproliferative diseases (11). The relative risk is most increased for hepatocellular carcinoma (2.5-fold) in diabetics. Type 2 diabetes is associated with 2 -fold increased risk of pancreatic cancer and endometrial cancer. Approximately (1.2-1.5 fold) increased risk of cancer is described for colorectum, bladder and non-Hodgkin lymphoma. The studies found a borderline 1.2 -fold increased risk of breast cancer. Only for prostate cancer is diabetes associated with a lower risk (12). According to some works type 2 diabetes is associated with a 10-fold increase risk of hepatocellular carcinoma (HCC) (13). There is theoretical assumption, that the improvement of 
insulin resistance may have a protective effect on the tumour prevalence (14). Options to reduce cancer risk in patients with type 2 diabetes will be subject of intense research in the coming years. National registry of patients with type 2 diabetes could significantly contribute to the explanation of the prevalence of cancer in patients with metabolic syndrome.

The aim of this study was to access the use of input data from the proposed National Registry of patients with type 2 diabetes. The main objective of the study was to assess the incidence of macrovascular complications (coronary heart disease and stroke, elevation of ALT and GGT and cancer) associated with the metabolic syndrome at the time of diagnosis type 2 diabetes.

\section{METHODS}

We were monitoring outpatients with newly diagnosed type 2 diabetes mellitus during the period of August 2007 - August 2011. The patients with previously treated type 2 diabetes mellitus were eliminated from the monitoring. Patients sent by general practitioners and various specialists ( 117 men, 83 women), aged from 30 to 92 years were conducted sampling blood glucose, glycosylated haemoglobin (HbAlc) by IFCC method (method of testing according to the International Federation of Clinical Chemistry and Laboratory Medicine), cholesterol, high density lipoprotein (HDL), low density lipoprotein (LDL), triglycerides (TG), atherogenic index, uric acid, alanine-aminotransferase (ALT), glutamyl transferase (GGT) of venous blood glucose. At-risk patients ( $47 \mathrm{men}, 33$ women) standard oral glucose tolerance test oGTT (75 g glucose) was made, which was crucial diagnostic value of glucose in the 2nd hour test. Values above $11.1 \mathrm{mmol} / 1$ were diagnostic for DM, ranging from 7.8 to 11.1 mmol/1 for impaired glucose tolerance (IGT), as recommended by the World Health Organization (WHO).

Laboratory analysis: Fasting glycaemia, total cholesterol, HDL cholesterol, LDL cholesterol, TG, ALT, GGT, HbAlc were determined by photometric analysis. We considered as pathological glucose values blood glucose values $>5.6 \mathrm{mmol} / 1$. In patients with impaired fasting glucose measured repeatedly $>7 \mathrm{mmol} / 1$ and in patients with glycemic $>11.1$ at any time during the day we did not have a standard oGTT. We considered as pathological values HbAlc IFCC > $4.7 \%$, cholesterol $>5.2 \mathrm{mmol} / 1$, LDL $>2.5 \mathrm{mmol} / 1$, TG $>1.94 \mathrm{mmol} / 1$, $\mathrm{HDL}<0.9 \mathrm{mmol} / 1$, creatinine $>107 \mathrm{~mol} / 1$, ALT $>0.55 \mathrm{~kat} / 1$, GGT > $0.45 \mathrm{~kat} / 1$.

Anthropometric examinations: At baseline, we measured the patients' height, weight, waist circumference, calculated body mass index (BMI) and blood pressure were measured. Waist circumference was measured in the horizontal plane in the middle of the distance between the upper edge of the iliac crest and the lower edge of the last rib in the breath.

At the time of diagnosis type 2 diabetes were followed occurrence of coronary heart disease, stroke, elevated serum levels of ALT and GGT and prevalence of cancer diseases. We compiled a questionnaire about smoking in the past and present. Interviews were conducted anonymously with 74 males and 67 females.

Statistical methods: Further mathematical processing was carried out in a database program EXCEL (Microsoft Office 2007). Statistical analyses were performed by the statistical program (CBT) compatible with Windows. Quantitative parameters characterizing individual files were expressed as median with appreciation of interquartile range.

Projects approved by the Regional Ethics Committee F.D.Roosevelt, Banska Bystrica.

\section{RESULTS}

We noted personal histories of patients and used data from medical records. We have recorded relatively low prevalence of known coronary artery disease in 34\% of men (40 of 117 ) and $19 \%$ of women (16 of 83) in our group of patients - Table No 2 . The prevalence of 
coronary heart disease was lower in our group in comparison to available statistics in adults (19-34\% and $45 \%)$.

Table 2. The number of patients with coronary heart disease(CHD) at the time of diagnosis of type 2 diabetes

\begin{tabular}{|c|c|c|}
\hline \multicolumn{3}{|c|}{ Incidence of CHD } \\
\hline Age group & Women & Men \\
\hline $\mathbf{3 0 - 3 9}$ & & \\
\hline $\mathbf{4 0 - 4 9}$ & & 1 \\
\hline $\mathbf{5 0 - 5 9}$ & 2 & 5 \\
\hline $\mathbf{6 0 - 6 9}$ & 3 & 16 \\
\hline $\mathbf{7 0 - 7 9}$ & 6 & 6 \\
\hline $\mathbf{8 0 - 8 9}$ & 5 & 10 \\
\hline $\mathbf{9 0 - 9 9}$ & & 2 \\
\hline
\end{tabular}

It is advisable to evaluate screening methods for detecting latent cardiovascular disease. Some patients may have latent coronary heart disease at the time of type 2 diagnosis. Therefore, it was important to conduct ECG (electrocardiogram) in patients without documentation of the ECG. We have recorded the new ischaemic changes in the electrocardiogram in two patients with newly diagnosed type 2 diabetes. The patients subsequently underwent coronary angiography and percutaneous transluminal angioplasty (PTA). We recommended ECG monitoring in the patients with newly diagnosed type 2 diabetes.

Metabolic syndrome - a cluster of conditions that includes: abdominal obesity, atherogenic dyslipidaemia (high level of triglycerides, low levels of HDL cholesterol) elevated blood pressure, insulin resistance (frequently manifested glucose intolerance), proimflammatory state and prothrombotic state increases the risk of coronary heart disease (15). Other possible factor including: age, family history, sex (males, women after menopause), smoking, physical inactivity, high stress), sleep apnea. Patients with type 2 diabetes are at higher risk of cardiovascular disease compared with those without diabetes.

The highest occurrence of the newly diagnosed type 2 diabetes was recorded within the group aged 60 to 69 years ( 42 males and 24 females). According to the results of HbAlc IFCC/DCCT (median males 5.9/7.5, median females 5.7/7.3), within all age categories and irrespectively of the gender, we may conclude a relatively early detection of the disease, suggesting a good cooperation with general practitioners and specialists in our cohort study of outpatients.

All patients within the monitored population were in the overweight range (BMI 25.0 29.9) and class I obesity (BMI 30.0 - 34.9). Waist circumference measurement in our cohort study confirmed that the IDF (International Diabetes Federation) criteria for abdominal obesity in 2005 defined waist circumference $\geq 80 \mathrm{~cm}$ for non-pregnant women and $\geq 94 \mathrm{~cm}$ for men are more favourable to the earlier detection and treatment of the metabolic syndrome than the NCEP -ATP (The National Cholesterol Education Program, Adult Treatment Panel) criteria) (16). Early lifestyle changes before approaching IDF waist circumference values could significantly prevent occurrence of type 2 diabetes. Waist circumference of our patients was approaching to the less stringent NCEP - ATP criteria for abdominal obesity (median $107 \mathrm{~cm}$ in males, median $105 \mathrm{~cm}$ in females).

We have recorded high prevalence of arterial hypertension in $72 \%$ of men (82 of 117) and 
in $80 \%$ of women ( 66 of 83 ). The majority of patients were adequately treated by the general practitioners (GP) or internist with the use of ACE inhibitors (Angiotensin Converting Enzyme) or ARBs (Angiotensin II receptor blockers) as a drug of first choice. We noted also a good management of arterial hypertension treatment at the time of diagnosis of type 2 diabetes mellitus (median males 120/80, median females 130/80), which could have an effect on reducing cardiovascular morbidity and mortality.

We have found treatment of dyslipidaemia in 117 patients with no history of type 2 diabetes at the time of diagnosis ( 64 men of $117,55 \%$ ) and ( 42 women of $83,51 \%$ ). For all subjects dyslipidemia was defined using National Cholesterol Education Program Adult Treatment panel III criteria (16). We have not found lipid profiles in 20 men and 14 women.

We identified gaps in management of the treatment of dyslipidaemia of pre-diabetic patients, where the patients with newly diagnosed type 2 diabetes mellitus did not reach the target value of LDL cholesterol in line with recommendations (median males 3.11 mmol/l, median females $3.22 \mathrm{mmol} / \mathrm{l}$ ). We have recorded elevated LDL levels $>2.5 \mathrm{mmol} / \mathrm{l}$ in $77 \%$ of men (75 of 97) and in $74 \%$ of women (51 of 69 ).We have recorded HDL levels < $0.9 \mathrm{mmol} / \mathrm{l}$ in $24 \%$ of men ( 26 of 107) and in $9 \%$ of women (51 of 69).We have recorded TG levels > $1.94 \mathrm{mmol} / \mathrm{l}$ in $56 \%$ of men (63 of 112) and in $52 \%$ of women (41 of 79) .

Based on an anonymous questionnaire study we have observed a high prevalence of smoking in the distant past and past pre-diabetes. In the past or past pre-diabetes had smoked $29.9 \%$ of women and $75.5 \%$ of men in our cohort study. Consumption of 20 cigarettes per day was reported by $1.5 \%$ of women and $33.8 \%$ of men. Active smoking was reported by $11.94 \%$ of women and $13.5 \%$ of men and passive smoking by $2.99 \%$ of women and $8.11 \%$ of men one year after education.

Risk factors for a stroke include high blood pressure, atrial fibrillation, hyperglycemia, low high - density lipoprotein (HDL), high triglycerides (TG), high low - density lipoprotein (LDL), hyperuricemia, lifestyle factors (i.e.smoking, alcohol consumption, central obesity, no rational diet, stress) and alterable risk factors ( age and smoking). We have recorded prevalence after stroke in $12 \%$ of men (14 of 117) and in $7 \%$ of women ( 6 of 83 ) in our group of patients - table No 3 . About $16 \%-24 \%$ of patients after stroke is expected to develop type 2 diabetes later in life (18).

Table 3.The Number of patients with stroke at the time of diagnose of type 2 diabetes

\begin{tabular}{|c|c|c|}
\hline \multicolumn{3}{|c|}{ Incidence of stroke } \\
\hline Age group & Women & Men \\
\hline $\mathbf{3 0 - 3 9}$ & & \\
\hline $\mathbf{4 0 - 4 9}$ & & \\
\hline $\mathbf{5 0 - 5 9}$ & 1 & 6 \\
\hline $\mathbf{6 0 - 6 9}$ & 2 & 4 \\
\hline $\mathbf{7 0 - 7 9}$ & 2 & 3 \\
\hline $\mathbf{8 0 - 8 9}$ & 1 & 1 \\
\hline $\mathbf{9 0 - 9 9}$ & & \\
\hline
\end{tabular}

We have recorded prevalence of elevated ALT levels > 0.55 in $45 \%$ of men (51 of 113) and in $45 \%$ of women ( 34 of 76 ). 4 men and 7 women didn't have laboratory values of ALT on admission investigation. We have recorded prevalence of elevated GGT levels $>0.45$ in $81 \%$ 
of men ( 90 of 111) and in $68 \%$ of women (52 of 77). 6 men and 6 women didn't have laboratory values of GGT on admission investigation. Data are shown in tables No 4 and 5 . We did not realize ultrasonographic examination in our group of patients. We can only assume, that ALT and GGT elevation is associated with hepatic steatosis and metabolic syndrome. In the initial education $15 \%$ of men and $3 \%$ of women have reported sporadic alcohol intake. We have had no patients with other liver disorders such as autoimmmune hepatitis or viral hepatitis.

Table 4.The number of patients, the average value of ALT ( kat/l) in patients with newly diagnosed type 2 diabetes expressed by median $(\operatorname{Med}(\mathrm{x}))$ and interquartile range $\left(\mathrm{R}_{\mathrm{g}}\right)$

\begin{tabular}{|c|c|c|c|c|c|c|}
\hline \multirow{2}{*}{ Age group } & \multicolumn{3}{|c|}{ WLT [ $\boldsymbol{\mu k a t / 1 ~ ] ~}$} & \multicolumn{3}{c|}{ Men } \\
\cline { 2 - 7 } & $\operatorname{Med}(\mathrm{x})$ & $\mathrm{R}_{\mathrm{Q}}$ & $\begin{array}{c}\text { number } \\
\text { of } \\
\text { patients }\end{array}$ & $\operatorname{Med}(\mathrm{x})$ & $\mathrm{R}_{\mathrm{Q}}$ & $\begin{array}{c}\text { number } \\
\text { of } \\
\text { patients }\end{array}$ \\
\cline { 2 - 7 } $\mathbf{3 0 - 3 9}$ & 0 & 0 & 0 & 0.66 & 0.39 & 3 \\
\hline $\mathbf{4 0 - 4 9}$ & 0.56 & 0.55 & 4 & 0.79 & 0.69 & 11 \\
\hline $\mathbf{5 0 - 5 9}$ & 0.67 & 0.55 & 19 & 0.55 & 0.24 & 26 \\
\hline $\mathbf{6 0 - 6 9}$ & 0.63 & 0.36 & 24 & 0.55 & 0.36 & 43 \\
\hline $\mathbf{7 0 - 7 9}$ & 0.43 & 0.26 & 19 & 0.44 & 0.31 & 17 \\
\hline $\mathbf{8 0 - 8 9}$ & 0.31 & 0.17 & 10 & 0.39 & 0.31 & 11 \\
\hline $\mathbf{9 0 - 9 9}$ & 0 & 0 & 0 & 0.41 & 0.07 & 2 \\
\hline
\end{tabular}

Table 5. The number of patients, the average value of GGT ( kat/l) in patients with newly diagnosed type 2 diabetes expressed by median $(\operatorname{Med}(x))$ and interquartile range $\left(R_{Q}\right)$

\begin{tabular}{|c|c|c|c|c|c|c|}
\hline \multirow{2}{*}{ Age group } & \multicolumn{3}{|c|}{ Women } & \multicolumn{3}{c|}{ Men } \\
\cline { 2 - 7 } & Med(x) & $\mathrm{R}_{\mathrm{Q}}$ & $\begin{array}{c}\text { number } \\
\text { of } \\
\text { patients }\end{array}$ & Med(x) & $\mathrm{R}_{\mathrm{Q}}$ & $\begin{array}{c}\text { number } \\
\text { of } \\
\text { patients }\end{array}$ \\
\hline $\mathbf{3 0 - 3 9}$ & 0 & 0 & 0 & 1.53 & 0.24 & 3 \\
\hline $\mathbf{4 0 - 4 9}$ & 0.46 & 0.22 & 4 & 0.91 & 0.80 & 11 \\
\hline $\mathbf{5 0 - 5 9}$ & 0.99 & 1.03 & 20 & 0.93 & 0.47 & 26 \\
\hline $\mathbf{6 0 - 6 9}$ & 0.61 & 0.26 & 24 & 0.79 & 0.80 & 42 \\
\hline $\mathbf{7 0 - 7 9}$ & 0.46 & 0.29 & 19 & 0.63 & 0.48 & 16 \\
\hline $\mathbf{8 0 - 8 9}$ & 0.40 & 0.21 & 10 & 0.56 & 0.43 & 11 \\
\hline $\mathbf{9 0 - 9 9}$ & 0 & 0 & 0 & 0.89 & 0.38 & 2 \\
\hline
\end{tabular}


In total of 196 patients with newly diagnosed type 2 diabetes we have seen in 10 of them the incidence of cancer diseases. We have recorded prevalence $5 \%$ in women (4 of 82 ) and prevalence $5.26 \%$ in men (6 of 114). In the studied group of patients we have recorded the occurrence of colon cancer in men over 64 years old and the occurrence of breast cancer, endometrial cancer and colon cancer in women over 62 years old. The prevalence of type 2 diabetes and the relative incidence of cancer increases exponentially with age. More than $80 \%$ of cancer being diagnosed in persons aged 55 and over (11).

Table 6. The number of patients with newly diagnosed type 2 diabetes and cancer

\begin{tabular}{|c|c|c|c|c|}
\hline Sex & \multicolumn{2}{|c|}{ Men } & \multicolumn{2}{|l|}{ Women } \\
\hline Age (years) & \multicolumn{2}{|c|}{$64-89$} & \multicolumn{2}{|c|}{$26.9-32.3$} \\
\hline BMI $\left(\mathrm{kg} / \mathrm{m}^{2}\right)$ & \multicolumn{2}{|c|}{$62-75$} & \multicolumn{2}{|l|}{$26.9-36$} \\
\hline \multirow{3}{*}{$\begin{array}{l}\text { Number of patients } \\
\text { with cancer history }\end{array}$} & \multirow{3}{*}{ Colon cancer } & \multirow{3}{*}{6} & Breast cancer & 2 \\
\hline & & & Colon cancer & 1 \\
\hline & & & Endometrial cancer & 1 \\
\hline $\begin{array}{l}\text { Number of patients with cancer } \\
\text { history before the occurrence } \\
\text { of type } 2 \mathrm{DM}\end{array}$ & \multicolumn{2}{|l|}{6} & \multicolumn{2}{|l|}{5} \\
\hline $\begin{array}{l}\text { Number of patients with a his- } \\
\text { tory of smoking before the } \\
\text { diagnosis of cancer }\end{array}$ & \multicolumn{2}{|l|}{0} & \multicolumn{2}{|l|}{0} \\
\hline
\end{tabular}

Coronary heart disease occurs in patients with type 2 diabetes early and is more serious than in non diabetics (1). The prevalence of coronary heart disease was lower in our group in comparison to available statistics in adults (19-34\% and 45\%), but some patients may have latent coronary heart disease at the time of type 2 diabetes diagnosis. More than 50\% of diabetics die of coronary heart disease (1). In a study group of 3266 patients being referred for coronary angioplasty ( $17 \%$ of patients, $n=556$ ) have known diabetes mellitus and $17.9 \%$ of patients, $n=486$ ) had newly diagnosed type 2 diabetes (19). In a study group of 7310 patients who have undergone coronary bypass operations between 1996 - 2003 the prevalence of undiagnosed DM was $5.2 \%$. The patients more frequently required resuscitation and reintubation and often showed a longer period of ventilation. Perioperative mortality rate was highest in this group (20).

We have recorded prevalence after stroke in 12\% of men (14 of 117) and 7\% of women (6 of 83 ) in our group of patients. About $16 \%-24 \%$ of patients after stroke is expected to develop type 2 diabetes later in life (18). The study enrolled 89 patients with acute ischaemic stroke and no history of diabetes. Thirty seven (38.5\%) of patients had impaired glucose tolerance at discharge and twenty six (27.1\%) after 3 months. Forty-four (45.8\%) had diabetes at discharge and 36 (37.5\%) at 3 month (21). In 2004 stroke was noted in 16\% of diabetes-related death among people age 65 years or older in the United States (22).

The risk of stroke is two to four times higher in diabetic subjects compared with nondiabetic subjects (8). 1-percentage point increase in glycosylated haemoglobin level is related to the risk of stroke. The stroke risk is 17 times higher (23). The relative risk of stroke is increased 4-fold in persons with systolic blood pressure over $160 \mathrm{mmHg}$ and diastolic blood pressure over $95 \mathrm{mmHg}$. The risk of stroke is increased 2 -fold in person, if the diastolic blood pressure is elevated more than $7.5 \mathrm{mmHg}$. In the Copenhagen Stroke Study $6 \%$ of patients with acute ischaemic stroke had undiagnosed diabetes (24) . 
We have recorded prevalence of elevated ALT levels $>0.55$ in $45 \%$ of men (51 of 113) and $45 \%$ of women (34 of 76). 4 men and 7 women didn't have laboratory values of ALT on admission investigation. We have recorded prevalence of elevated GGT levels $>0.45$ in $81 \%$ of men (90 of 111) and 68\% of women 68\% (52 of 77). 6 men and 6 women didn't have laboratory values of GGT on admission investigation. We did not do ultrasonographic examination in our group of patients. We can only assume, that ALT and GGT elevation is associated with hepatic steatosis and metabolic syndrome. In the initial education $15 \%$ of men and $3 \%$ of women have reported sporadic alcohol intake. We have had no patients with other liver disorders such as autoimmmune hepatitis or viral hepatitis.

At baseline patients are educated by the inappropriate consumption of any alcohol. The modest alcohol intake leads to an increase in body weight. Alcohol has a high energy content $(29 \mathrm{~kJ} / \mathrm{g})$ and is oxidized immediately after ingestion. Alcohol must be oxidized first before other energy sources. Alcohol suppresses oxidation of other energy sources (protein, carbohydrates, fats) - making it more difficult to mobilize when alcohol is present. However some studies conclude that moderate alcohol consumption increases insulin sensitivity and is associated with decreased incidence of type 2 diabetes $(25,26,27)$. Annex table No 7 . compares the correlation between the prevalence of type 2 diabetes, ischaemic heart disease, alcoholic cirrhosis and per capita alcohol consumption in selected European countries (e.g. France and Sweden). According to the World Health Organisation (WHO), France is a country with a total adult per capita alcohol consumption per year: 14.5 litres. Czech people consume two highest amount of alcohol per capita of the countries listed in the table No 7. France has the lowest prevalence of coronary heart disease, but the highest prevalence of diabetes mellitus from the nine European countries listed in the table No 7, according to the IDF estimates for the year 2010.

The incidence of alcoholic cirrhosis is $12 / 100000$ inhabitants per year. Comparison to the Slovak Republic, where there is the incidence of alcoholic cirrhosis 27/100 000 inhabitants per year. Under the Swedish law on alcohol, private individuals are prohibited importing alcoholic beverages. According to the WHO report 2004, total adult per capita alcohol consumption is 71 i.e. at least in those countries listed in the table No 7 . Sweden has a higher prevalence of coronary heart disease than France, but the lowest diabetes prevalence of nine European countries listed in the table No 7. The incidence of alcoholic cirrhosis is 4/100 000 inhabitants per year. In recent years will have many other studies the aim to investigate alcohol consumption in relation to the incidence of type 2 diabetes. Now there is the time we can say there are individual and population differences between the safe recommended alcohol doses. Coincidence of other factors contributing to the prevalence of obesity and other chronic conditions not related to the prevalence of type 2 diabetes is important too.

In a study on 101 patients with type 2 diabetes $60.3 \%$ of patients had verified steatosis by MR spectroscopy. In this study $68 \%$ patients with type 2 diabetes had normal ALT and GGT values (30). Meta-analysis of 7 large cross-sectional studies of 2,500 people found, that ultrasonography findings of steatosis is an independent risk factor for cardiovascular events (31). Among those with steatohepatitis develops liver cirrhosis approximately in 1 of 30 patients. Patients with non alcoholic steatohepatitis are at greater risk for developing cirrhosis than patients with steatosis (32). Non alcoholic steatohepatitis can coexist with other diseases (e.g, chronic viral hepatitis, type 2 diabetes or alcohol abusus). There are factors, that can increase the risk of progression liver disease. There is a large percentage of patients with steatosis. They should be stratified in terms of progression to cirrhosis by hepatologist. It would require much closer collaborattion between diabetologist and hepatologist in the future.

British regional heart study was conducted 24 years and was attended by 6997 men aged $40-59$ years with no history of cardiovascular events or type 2 diabetes. Study has shown 
Table 7. The difference in the prevalence of type 2 diabetes, CHD, alcohol liver cirrhosis and alcohol consumption per capita in selected European countries.

\begin{tabular}{|c|c|c|c|c|c|c|c|}
\hline & $\begin{array}{c}\text { Beer } \\
\text { consumption } \\
\text { per capita } \\
\text { (liter) }\end{array}$ & $\begin{array}{c}\text { Wine } \\
\text { consumption } \\
\text { per capita } \\
\text { (liter) }\end{array}$ & $\begin{array}{c}\text { Spirit } \\
\text { consumuption } \\
\text { per capita } \\
\text { (liter) }\end{array}$ & $\begin{array}{c}\text { Total alcohol } \\
\text { consumption } \\
\text { per capita } \\
\text { (liter) }\end{array}$ & $\begin{array}{c}\text { Prevalence } \\
\text { of DM (\%) } \\
\text { according to } \\
\text { national esti- } \\
\text { mates for the } \\
\text { year 2010 }\end{array}$ & $\begin{array}{c}\text { Prevalence } \\
\text { of CHD } \\
\text { per 1000 } \\
\text { population }\end{array}$ & $\begin{array}{c}\text { Prevalence } \\
\text { of alcohol } \\
\text { liver } \\
\text { cirrhosis } \\
\text { per } \\
\text { population }\end{array}$ \\
\hline GERMANY & 7.5 & 3.5 & 2.0 & 13.0 & 12 & 1.1 & 0.14 \\
\hline SPAIN & 4.5 & 5.0 & 2.5 & 12.0 & 8.7 & 0.54 & 0.11 \\
\hline SLOVAKIA & 5.5 & 2.0 & 5.5 & 12.5 & 7.7 & - & 0.27 \\
\hline NETHERLANDS & 5.0 & 3.0 & 2.0 & 10.0 & 7.7 & 0.8 & 0.042 \\
\hline DENMARK & 6.0 & 5.0 & 0.25 & 11.25 & 7.7 & 0.9 & 0.125 \\
\hline SWEDEN & 3.5 & 2.5 & 1.0 & 7.0 & 7.3 & 0.9 & 0.04 \\
\hline FRANCE & 2.5 & 9.0 & 3.0 & 14.5 & 9.4 & 0.4 & 0.12 \\
\hline ITALY & 1.0 & 7.5 & 0.5 & 9.0 & 8.8 & 0.6 & 0.11 \\
\hline CZECH & 1.0 & 2.0 & 4.0 & 16.0 & 8.7 & 1.4 & 0.13 \\
\hline
\end{tabular}

Adapted by Diabetes Atlas IDF 2010 (28) and according to the WHO. Global Satus report 2004 on Chronic mortality and Alcohol 2004 (29)

that elevated GGT levels significantly increased the patient risk of stroke, fatal coronary events and cardiovascular events independently of other risk factors in the Framingham score (8). In the Hoorn study there was shown that elevated ALT levels predicts cardiovascular events (33). Meta-analysis of 11 prospective studies have found, that elevated GGT is an independent predictor of long-term cardiovascular events in both sexes (34). During the years $2006-2007$ the study was conducted in Iran including 7554 patients aged $6-18$ years with results that elevated ALT, AST and ALP levels in children and adolescents were associated with central obesity, elevated TG, reduced HDL and impaired fasting glucose (35).

Prevalence of cancer diseases was recorded in 5\% of women and $5.26 \%$ of men with type 2 diabetes mellitus. In the studied group of patients there was recorded the occurrence of colon cancer in men over 64 years old and the occurrence of breast cancer, endometrial cancer and colon cancer in women over 62 years old. We did not record the occurrence of hepatocellular carcinoma, although the relative risk for HCC is most increased in diabetics.

The prevalence of cancer appears to be rising with a longer duration of type 2 diabetes. An casual finding of cancer in an advanced stage is still common. Universal screening programme for cancer associated with metabolic syndrome has not been still implemented in patients with type 2 diabetes. Table No. 8 shows the mortality rates per 100000 people for cancer in the countries of the European Union in 2010 (6). According to the Eurostat date published in 2012 standardised death due to cancer in Slovakia was 197 per 100000 population (i.e. the second highest in the EU countries). 
Table 8. Standardised death due to cancer in EU per 100000 population in 2010 (6)

\begin{tabular}{|l|c|l|c|l|c|l|l|l|l|l|l|}
\hline Romania & 180 & Poland & 196.5 & Ireland & 169 & Denmark & & Sweden & 141 & Spain & 152.4 \\
\hline Bulgaria & 156.4 & Czech & 195 & Estonia & 185.3 & Cyprus & 117.4 & Malta & 151.7 & Portugal & 156.5 \\
\hline Hungary & 238.8 & Austria & 155.6 & UK & 170.6 & Belgium & & Finland & 138 & & \\
\hline Slovakia & 197.2 & Lithuanian & 187 & Greece & 149 & Italy & 156.8 & France & 161 & & \\
\hline Slovenia & 196.26 & Germany & 158.6 & Netherlands & 182.8 & Luxemburg & 156.9 & Latvia & 193.9 & & \\
\hline
\end{tabular}

\section{CONCLUSIONS}

Screening for macrovascular complications (coronary heart disease and stroke) at time of diagnosis type 2 diabetes would be useful in determining of individual treatment target values. Although we recorded relatively lower prevalence of coronary heart disease than the available statistic, we do not exclude the presence of asymptomatic coronary heart disease. We detect presence of risk factors for coronary heart disease.

According to the results of HbAlc IFCC/DCCT (median males $5.9 \% / 7.5 \%$, median females $5.7 / 7.3$, within all age categories and irrespectively of the gender, we may conclude a relatively early detection of the disease in our cohort group of patients.

We note also a good management of arterial hypertension treatment at the time of diagnosis of diabetes mellitus type 2 (median males 120/80 mm/Hg, median females 130/80 $\mathrm{mm} / \mathrm{Hg}$.

We identified gaps in management of the treatment of dyslipidaemia of pre-diabetic patients, where the patients with newly diagnosed type 2 diabetes mellitus did not reach the target value of LDL cholesterol in line with recommendations (median males 3.11 mmol/l, median females $3.22 \mathrm{mmol} / \mathrm{l}$ ).

Elevated GGT and ALT are independent risk factors for coronary heart disease and stroke in our group of patients. Cigarette smoking in our cohort of patients is declining. Patients with elevated ALT and GGT levels are a primary target group for alcohol education. Alcohol education includes information about the effects of alcohol consumption. Overall it is estimated, that $15-30 \%$ of NASH patients go on to develop cirrhosis in a time interval 10 years. Currently steatofibrosis is one of the causes of liver transplantation. Ultrasonographic finding of steatosis is an independent risk factor for cardiovascular events. We did not record the occurrence of hepatocellular carcinoma, altough the relative risk for HCC is most increased in diabetics.

In the studied group of patients we have recorded the occurrence of colon cancer in men over 64 years old and the occurrence of breast cancer, endometrial cancer and colon cancer in women over 62 years old. Our study was limited to the small population size.

\section{REFERENCES}

1. Belicová M. Diabetes mellitus a srdce. In: Mokáñ M, Martinka E, Galajda P, editors. Diabetes mellitus a vybrané metabolické ochorenia: 1nd ed. Martin: Vydavatel'stvo P + M; 2008. kap. 10.1: p. 649 - 665 .

2. ADVANCE Collaborative group. Intensive blood glucose control and vascular outcomes in patients with type 2 diabetes. N Engl J Med 2008; 358: 2560 - 2572 .

3. Cefalu W, Watson K. Intensive glycemic control and cardiovascular disease observations. From the Accord Study. Now what can a clinician possible think. Diabetes 2008; 57: $1163-1165$.

4. Skyler JS, Bergenstal R, Bonow RO, et al. Intensive glycemic control and the prevention of cardiovascular events: Implications of the Accord, Advance and VA Diabetes Trials. Circulation 2009; 119: 351- 357.

5. http://www.infostat.sk/vdc/sk/

6. http://epp.eurostat.ec.europa.eu/portal/page/portal/eurostat/home/ 
7. Tan HH, Chang JP. Non-alcoholic fatty liver disease proceedings of Singapore. Healthcare 2010; 19(1): 36 - 49.

8. Wannamethee SG, Lennon L, Shaper AG. The value of gammaglutamyltransferase in cardiovascular risk prediction in men without diagnosed cardiovascular disease or diabetes. Atherosclerosis 2008; 201: 168 - 175.

9. Trappoliere M, Tuccillo C, Federico A et al. The treatment of NAFLD. Eur R Med Pharmacol Sci 2005; 9(5): 299-304.

10. Giovannuci E, Harlan DM, Archer MC et al. Diabetes and cancer: a consensus report. CA Cancer Journal for Clinicians 2010; 60: $207-221$.

11. Sun G, Kashyap SR. Cancer risk in type 2 diabetes mellitus: Metabolic links and therapeutic considerations. Journal of Nutrition and Metabolism 2011; 708183 E pub 2011 JUN 1.

12. Haluzík Martin, Haluzík Michal. Diabetes a nádory. In: Kvapil M, editors: Diabetologie 2011: 1nd ed. Praha: Vydavatelstvo Triton 2011; p. $32-45$.

13. El-Serag HB, Tran T, Everhart JE. Diabetes increases the risk of chronic liver disease and hepatocellular carcinoma. Gastroenterology 2004; 126(2): $460-468$.

14. Galajda P, Mokáñ M. Diabetes mellitus a nádory. Diabetes a obezita 2011; 11(20): 1-11.

15. Scott M, Grund MD, Brewe B et al. Definition of metabolic syndrome. Circulation. 2004; 109: 433-438.

16. Definition of Metabolic Syndrome. Report of the National Heart, Lung, and Blood institute, American Heart Association. Conference on Scientific Issues Related to Definition. Clin. Biochem. Rev. 2004; 25 (3): 195 - 198.

17. http://www.idf.org/metabolic-syndrome

18. Sander D, Sander K, Poppert H. Stroke in type 2 diabetes. The British Journal of Diabetes and Vascular Disease $2008 ; 8: 222$ - 229 .

19. Taubert G, Winkelmann BR, Schleiffer T et al. Prevalence, predictors and consequences of unrecognized diabetes mellitus in 3266 patients scheduled for coronary angiography. American Heart Journal 2003; 145:285 291.

20. Lauruschkat AH, Arnrich B, Albert AA et al. Prevalence and risks of undiagnosed diabetes mellitus in patients undergoing coronary artery bypass grafting. Circulation 2005; 112: $2397-2402$.

21. Vancheri F, Curcio M, Burgio A, et al. Impaired glucose metabolism in patients with acute stroke and no previous diagnosis of diabetes mellitus. $\mathrm{Q} \mathrm{J}$ Med 2005; 98: $871-878$.

22. http://diabetes.niddk.nih.gov/DM/PUBS/statistics/\#hds (National Institute of Diabetes and Digestive and Kidney Diseases (NIDDK), National Institutes of Health (NIH))

23. Selvin E, Marinnopoulos S, Berkenblit G et al. Meta- analysis: glycosylated hemoglobin and cardiovascular disease in diabetes mellitus. Ann Intern Med 2004; 141: 421- 431.

24. Jorgensen HS, Nakayma H, Raaschou HO, Olsen TS. Stroke in patients with diabetes. The Copenhagen Stroke Study. Stroke 1994; 25: 1977- 84.

25. Bell RA, Mayer - Davis EJ et al. Associations between alcohol consumption and insulin sensivity and cardiovascular disease risk factors: the Insulin Resistance and Atherosclerosis Study. Diabetes Care 2000; $23: 1630$ 1660.

26. Facchini F, Chen YD, Reaven GM. Light - to moderate alcohol intake is associates with enhanced insulin sensivity. Diabetes Care 1994; 17: 115 - 119.

27. Mudra J, Rušavý Z: Alkohol a diabetes. Interní medicína pro prax 2004; 7: 347 - 351.

28. http://www.diabetesatlas.org/content/diabetes (International Diabetes Federation )

29. http://www.who.int/substance_abuse/publications/en/1_all_country_profiles_euro.pdf ( WHO Global Status Report on Alcohol 2004 )

30. Petit JM, Guiu B, Terriat B et al. Nonalcoholic fatty liver is not associated with carotid intima-media thickness in type 2 diabetic patients. The Journal of Clinical Endocrinology and Metabolism 2009; 94 : 4103-6.

31. Szántová M. Metabolický syndróm a pečeñ. Súč Klin Pr 2011; 2: 45-52.

32. Perseghin G. Lipids in the wrong place: Visceral fat and nonalcoholic steatohepatitis: Diabetes Care 2011; 34 : S367-S370.

33. Schindhelm RK, Dekker JM, Nijpels G, et al.: Alanine aminotransferase predict coronary heart disease events: a 10-years follow-up of the Hoorn Study. Atherosclerosis 2007; 191: 391-396.

34. Targher G, Day CP, Bonora E. Risk of cardiovascular disease in patients with nonalcoholic fatty liver disease. N Eng J Med 2010; 363(14): 1341-1350.

35. Kelishadi R, Cook SR, Adibi A, Faghihimani Z, Ghatrehsamani S, Beihaghi A, Salehi H, Khavarian N, Poursafa P: Association of the components of the metabolic syndrome with non-alcoholic fatty liver disease among normal-weight, overweight and obese children and adolescent. Diabetol Metab Syndr. 2009;1: 29.

Received: January, 26, 2013

Accepted: March, 26, 2013 